\title{
Modifying Precursor Solutions to Obtain Screen-Printable Inks for Tungsten Oxides Electrochromic Film Preparation
}

\author{
Kaiyue Guo ${ }^{1}$, Guanguang Zhang ${ }^{1}$, Yujie Long ${ }^{1}$, Honglong Ning ${ }^{1, *(\mathbb{O})}$, Zhuohui $\mathrm{Xu}^{2}{ }^{2}$, Tian Qiu ${ }^{3}$, \\ Dongxiang Luo ${ }^{4,5}$, Muyun Li ${ }^{1}$, Rihui Yao ${ }^{1, * \mathbb{D}}$ and Junbiao Peng ${ }^{1}$
}

1 State Key Laboratory of Luminescent Materials and Devices, Institute of Polymer Optoelectronic Materials and Devices, South China University of Technology, Guangzhou 510640, China; 201836320090@mail.scut.edu.cn (K.G.); msgg-zhang@mail.scut.edu.cn (G.Z.); 201930173073@mail.scut.edu.cn (Y.L.); 1lmyscut@163.com (M.L.); psjbpeng@scut.edu.cn (J.P.)

2 Guangxi Key Lab of Agricultural Resources Chemistry and Biotechnology, Yulin Normal University, Yulin 537000, China; xzh@ylu.edu.cn

3 Department of Intelligent Manufacturing, Wuyi University, Jiangmen 529020, China; qiutian@ustc.edu

4 School of Materials and Energy, Guangdong University of Technology, Guangzhou 510006, China; luodx@gdut.edu.cn

5 Institute of Semiconductors, South China Normal University, Guangzhou 510631, China

* Correspondence: ninghl@scut.edu.cn (H.N.); yaorihui@scut.edu.cn (R.Y.); Tel.: +86-20-8711-4525 (H.N.)

check for updates

Citation: Guo, K.; Zhang, G.; Long, Y.; Ning, H.; Xu, Z.; Qiu, T.; Luo, D.; Li, M.; Yao, R.; Peng, J. Modifying Precursor Solutions to Obtain Screen-Printable Inks for Tungsten Oxides Electrochromic Film Preparation. Coatings 2021, 11, 872. https://doi.org/10.3390/ coatings 11080872

Academic Editor: Chen Tei-Chen

Received: 23 June 2021

Accepted: 19 July 2021

Published: 22 July 2021

Publisher's Note: MDPI stays neutral with regard to jurisdictional claims in published maps and institutional affiliations.

Copyright: (c) 2021 by the authors. Licensee MDPI, Basel, Switzerland. This article is an open access article distributed under the terms and conditions of the Creative Commons Attribution (CC BY) license (https:/ / creativecommons.org/licenses/by/ $4.0 /)$.

\begin{abstract}
Tungsten trioxide $\left(\mathrm{WO}_{3}\right)$ is used to prepare the important electrochromic layer of the electrochromic device as a wide bandgap semiconductor material. In this study, $\mathrm{WO}_{3}$ electrochromic film was successfully prepared by screen printing. To modify the thixotropy and wettability of the ink, polyvinyl alcohol (PVA) and 2-perfluoroalkyl ethanol (FSO) were added in the ammonium meta-tungstate (AMT) solution. We found that the PVA additive could improve the dynamic viscosity of the solution and modify the uniformity of the film. 2-Perfluoroalkyl ethanol (FSO) could lower the surface tension and increase the wettability of the AMT solution on the substrate. By observing the morphology of the printed films, the ink formulas for screen printing were selected. We found the annealing process could help remove PVA. Through characterization of electrochromic performance, it was found that the best performing device had $42.57 \%$ modulation and $93.25 \mathrm{~cm}^{2} \cdot \mathrm{C}^{-1}$ coloration efficiency (CE) for $600 \mathrm{~nm}$ light. This study showed great potential in the preparation of $\mathrm{WO}_{3}$ electrochromic devices by a low-cost screen-printing method.
\end{abstract}

Keywords: electrochromic; screen printing; polyvinyl alcohol (PVA); 2-perfluoroalkyl ethanol (FSO); ink formulas

\section{Introduction}

Nowadays, electrochromism has had applications in many fields such as energysaving smart windows [1-5], batteries [6], sensors [7], next-generation displays and wearable electronics [8]. Tungsten trioxide $\left(\mathrm{WO}_{3}\right)$ was the most widely studied and used electrochromic material. Not only does the raw material have high cost-performance, but also $\mathrm{WO}_{3}$ film has excellent electrochromic properties such as high optical contrast and low energy consumption [9]. There are many methods to prepare electrochromic films such as magnetron sputtering [10-12], ion plating and sol-gel [13-16]. Recently, there have been studies on the electrochromic film preparation by the hydrothermal method [17,18]. So far, as the mainstream industrial preparation method, magnetron sputtering requires complex equipment and process, which makes it hard to reduce the cost and further industrialize. To solve the cost problem, screen printing and inkjet printing have become the research emphasis of electrochromic film preparation because of their high cost-performance, simple process and low environmental requirements. Up to now, screen printing has been used in many fields. It is commonly used to prepare film in thermoelectric devices [19,20], flexible transparent electrode [21,22], organic semiconductor device [23] 
and sensors [24,25]. To date, screen-printable organic ink based on ECP-Magenta for electrochromic film preparation has been studied [26]. In this work, the ink formulas based on ammonium meta-tungstate (AMT) solution were studied to prepare $\mathrm{WO}_{3}$ electrochromic film by screen printing.

Many factors affect film formation in screen printing. It is a challenge to determine the appropriate materials and ratio of the screen-printable ink. Screen printing requires the ink to have high viscosity and low volatility [27]. However, the dynamic viscosity of most inorganic solutions cannot meet the requirements, so it is necessary to add some kinds of polymer to modify them. It is also a challenge to ensure the ink has good wettability on the substrate. This can be solved by adding surfactant to decrease the surface tension of the precursor solutions. Because most polymers affect the electrochromic performance of the film, it should be removed in annealing. Annealing temperature and time should be determined considering the decomposition of polymer and production of $\mathrm{WO}_{3}$. Meanwhile, in order to repeat the films, screen printing parameters including screen counting mesh [28], number of reprints and the distance between screen and substrate should be invariant.

In this work, ink formulas were studied to prepare $\mathrm{WO}_{3}$ electrochromic film by screen printing. Polyvinyl alcohol (PVA) was chosen to modify the dynamic viscosity of AMT solution because PVA is usually used as a common adhesive [29,30]. As a kind of surfactant, 2-perfluoroalkyl ethanol (FSO) was added to improve the wettability. The effects of PVA and FSO on dynamic viscosity, surface tension and contact angle of the precursor solutions were characterized. The morphology of the printed films helped select the screen-printable ink formulas. The changes in composition and transmittance of the films due to annealing were studied. Through electrochromic performance characterization, the best performing film was found and its performance was further characterized.

\section{Materials and Methods}

Ammonium meta-tungstate (AMT, $\left(\mathrm{NH}_{4}\right)_{6} \mathrm{H}_{2} \mathrm{~W}_{12} \mathrm{O}_{40} \cdot \times \mathrm{H}_{2} \mathrm{O}$ ) was dissolved in isopycnic distilled water to prepare the $0.1 \mathrm{~mol} / \mathrm{L}$ AMT solution. Different amounts of polyvinyl alcohol (PVA, 98-99\% hydrolyzed, high molecular weight) were added when AMT solution was stirred and heated at $95^{\circ} \mathrm{C}$. The mass fractions of PVA were $1.1 \%, 2.0 \%, 2.9 \%, 3.8 \%$, $4.7 \%, 5.6 \%$ and $6.5 \%$. The mass fraction of 2-perfluoroalkyl ethanol (FSO) was one threehundredth of the mass fraction of PVA, which respectively were $0.004 \%, 0.007 \%, 0.010 \%$, $0.013 \%, 0.016 \%, 0.019 \%$ and $0.022 \%$. FSO was dropped using a syringe after PVA was dissolved and the solution cooled. All the precursor solutions were stirred until uniform.

The mesh count of the printing screen was $450 \mathrm{~cm}^{-2}$. The distance between the screen and printing substrate was about $4 \mathrm{~mm}$. The precursor solution was printed on a clean ITO substrate $(2 \mathrm{~cm} \times 2 \mathrm{~cm})$ through the pattern $(1 \mathrm{~cm} \times 1 \mathrm{~cm})$ by screen printing. The film was printed twice with a single solution volume of $50 \mu \mathrm{L}$ and dried naturally for $30 \mathrm{~s}$ after screen printing.

It has been reported that the residues of PVA after thermal decomposition at $500{ }^{\circ} \mathrm{C}$ was about 5\% [31] and decomposition of AMT at no lower than $500{ }^{\circ} \mathrm{C}$ vaporized most $\mathrm{NH}_{3}$ and $\mathrm{H}_{2} \mathrm{O}$, producing $\mathrm{WO}_{3}$ [32,33]. Considering the thermal deformation of ITO glass, the films were annealed at $500{ }^{\circ} \mathrm{C}$ for an hour. The annealed films were packaged using the electrolyte solution (mixture of $50 \%$ volume fraction for both $1 \mathrm{~mol} / \mathrm{L}$ propylene carbonate solution of $\mathrm{LiClO}_{4}$ and $\mathrm{UV}$ curing adhesive, the type of UV-curing adhesive was Valigoo8500). The electrolyte solution was solidified under UV light ( $395 \mathrm{~nm})$ irradiation to prevent it from outflowing from the device.

The surface tension and the contact angle of AMT solution and the precursor solutions were measured by Attension Theta (Biolin Scientific, TL200, Gothenburg, Sweden). The dynamic viscosity of the AMT solution and the precursor solutions was measured using a rotational rheometer (Thermo Fisher Scientific, HAAKE MARS 40, Waltham, MA, USA). The morphology of the printed films was measured by the optical microscope (MSHOT, MJ30, Guangzhou, China). Fourier transform infrared spectroscopy (FT-IR) spectra of the unannealed and annealed films were recorded by an FT-IR spectrophotometer (SHI- 
MADZU IR Prestige-21, SHIMADZU, Tokyo, Japan) with an ITO glass substrate acting as a blank. The crystals of the unannealed and annealed films were distinguished by X-ray diffraction using $\mathrm{Cu} \mathrm{K} \alpha$ radiation (XRD, PANalytucal Empyrean DY1577, PANalytical, Almelo, The Netherlands), and the XRD patterns were analyzed using the software Jade 6.0. The thickness of all the annealed films were measured by a probe surface profiler (Veeco Dektak 150, Veeco, NY, USA). The transmittance of the unannealed and annealed films were measured by an ultraviolet spectrophotometer (SHIMADZE UV2600, SHIMADZU, Tokyo, Japan), with air acting as a blank. The current of the electrochromic test and the relationship between the change of transmittance and time were recorded by an electrochromic workstation (CH Instruments CHI 660E, CH Instruments, Shanghai, China) and a micro-spectrometer (Morpho PG2000, Morpho, Shanghai, China) respectively.

\section{Results and Discussion}

\subsection{Effect of Polyvinyl Alcohol (PVA) and 2-Perfluoroalkyl Ethanol (FSO) on Precursor Solutions and Film Formation}

Figure 1 shows the dynamic viscosity of all the precursor solutions. The measured dynamic viscosity of AMT solution was $1.08 \mathrm{mPa} \cdot \mathrm{s}$. It is shown in Figure 1 that the dynamic viscosities of the precursor solutions without FSO were all higher than that of the AMT solution, which illustrated that the addition of PVA could increase the dynamic viscosity. The dynamic viscosity of the precursor solutions without FSO had a non-linear rise from 1.70 to $103.27 \mathrm{mPa} \cdot \mathrm{s}$ with the increase in the mass fraction of PVA. Some studies indicated that the critical micelle concentration (CMC) of PVA-related material was in the range of $0.125-4.47 \mathrm{mg} / \mathrm{L}[34,35]$, so it could be speculated that for all the precursor solutions, PVA macromolecules had intermolecular forces and formed hydrogen bonds with each other because the concentration exceeded its CMC. Therefore, the reason for the non-linear rise of the dynamic viscosity was due to more intermolecular forces and hydrogen bonds between PVA macromolecules. It was found in Figure 1 that the dynamic viscosity of the precursor solutions with FSO increased from 2.16 to $163.61 \mathrm{mPa} \cdot \mathrm{s}$ with the increase in the mass fraction of PVA. The increasing tendency in the dynamic viscosity of the precursor solutions with FSO was similar to that of the precursor solutions without FSO, which illustrated that the dynamic viscosity was mainly affected by PVA. Figure 1 also showed that at the same PVA mass fraction, the dynamic viscosity of the precursor solutions with FSO was higher than that of the precursor solutions without FSO, proving that the addition of FSO could increase the dynamic viscosity. A study suggested that the increase of the dynamic viscosity might be caused by hydrogen bonds formed between the surfactant and polymer [36].

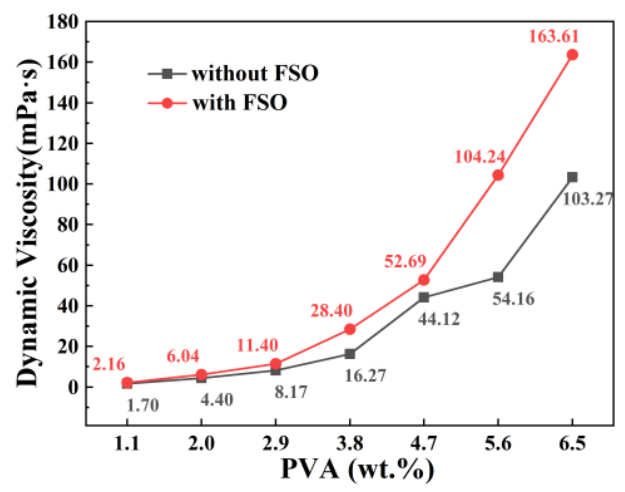

Figure 1. Precursor solutions dynamic viscosity.

Figure 2a showed the surface tension of all the precursor solutions. As shown in Figure 2a, the surface tension of the precursor solutions without FSO were within the range of $1.33 \mathrm{mN} / \mathrm{m}$ at around $52.96 \mathrm{mN} / \mathrm{m}$. The surface tension was almost unchanged with the increase of PVA mass fraction, indicating that PVA might reach saturation in the 
liquid surface because the concentration exceeded its CMC. The measured surface tension of AMT solution was $58.14 \mathrm{mN} / \mathrm{m}$, and the surface tensions of the precursor solutions without FSO were all lower than those of AMT solution, proving that PVA had surface activity. In the precursor solution, the FSO mass fraction increased with the PVA mass fraction increase because the ratio of FSO to PVA was constant. In general, because of high surface activity, FSO always tends to gather at the liquid surface, and the surface tension will decrease with the increase of its mass fraction. However, in Figure 2a, it can be seen that the surface tension of the precursor solutions with FSO increased first, and then decreased while obtaining the maximum at $3.8 \mathrm{wt}$.\% PVA. A possible explanation was that hydrogen bonds were formed between PVA and FSO at first, resulting in the surface tension increase. After hydrogen bonds reached saturation in the liquid surface, the increase of FSO mass fraction would decrease the surface tension. The surface tension of the precursor solutions without FSO was all below $23.00 \mathrm{mN} / \mathrm{m}$ while the surface tension of the precursor solutions with FSO was all over $51.00 \mathrm{mN} / \mathrm{m}$, which illustrated that the addition of FSO could greatly reduce the surface tension of the precursor solutions.

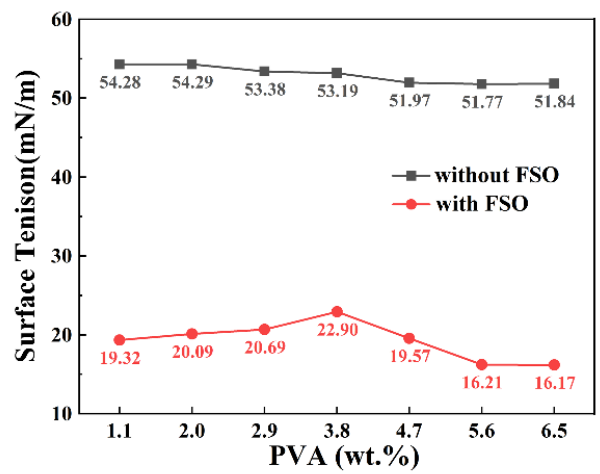

(a)

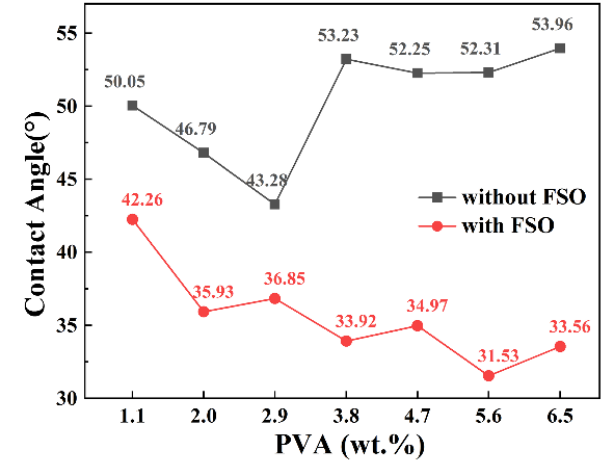

(b)

Figure 2. Precursor solutions: (a) surface tension, (b) contact angle at $20 \mathrm{~s}$.

The contact angle at $20 \mathrm{~s}$ of all the precursor solutions is shown in Figure 2b. Young's equation (Equation (1)) describes the relation between contact angle and surface tension for a liquid droplet on a smooth and uniform solid surface,

$$
\gamma_{\mathrm{sv}}=\gamma_{\mathrm{sl}}+\gamma_{\mathrm{lv}} \cos \theta
$$

where $\gamma_{\mathrm{sv}}, \gamma_{\mathrm{sl}}$ and $\gamma_{\mathrm{lv}}$ respectively denote the surface tensions of solid/air, solid/liquid and liquid/air interfaces; $\theta$ is the Young's contact angle. The measured contact angle of AMT solution was $51.31^{\circ}$. From Figure $2 b$, the contact angle of the precursor solutions without FSO was lower than that of AMT solution when PVA was no higher than $2.9 \mathrm{wt} . \%$ while the contact angle was higher than that of AMT solution when PVA was no lower than $3.8 \mathrm{wt} . \%$. The reason might be that when the concentration of PVA exceeded a critical value between $2.9 \mathrm{wt} . \%$ and $3.8 \mathrm{wt} . \%$, the surface tension between substrate and solution from being decreased to being increased because PVA entanglement structure changed. From Figure $2 b$, the contact angle of the precursor solutions with FSO had a fluctuant decline with the PVA mass fraction increase. The reason might be that FSO affected the surface tensions of liquid/air and solid/liquid through hydrogen bonds, resulting in the fluctuation of the contact angle. It was also found in Figure $2 b$ that at the same mass fraction of PVA, the contact angle of the precursor solutions with FSO were smaller than that of the precursor solutions without FSO, which indicated that the addition of FSO could improve the wettability of the precursor solution on the substrate by changing the surface tension.

The relation of contact angle with the time of all the precursor solutions is shown in Figure 3. From Figure 3a, the contact angle of the precursor solutions without FSO dropped all less than $6.21^{\circ}$ in $30 \mathrm{~s}$ and became stable at $30 \mathrm{~s}$. From Figure $3 \mathrm{~b}$, the contact angles of 
the precursor solutions with FSO all dropped more than $12.65^{\circ}$ in $30 \mathrm{~s}$ and continued to decrease at $30 \mathrm{~s}$. Comparing Figure $3 \mathrm{~b}$ with Figure $3 \mathrm{a}$, it was found that at the same mass fraction of PVA, the contact angle of the precursor solutions with FSO had faster descent than that of the precursor solutions without FSO, which illustrated the addition of FSO could accelerate the decreased spread of the contact angle by improving wettability. It could be speculated that the final stable contact angle of the precursor solutions with FSO would be much smaller than that of the precursor solutions without FSO, which might make the film more uniform.

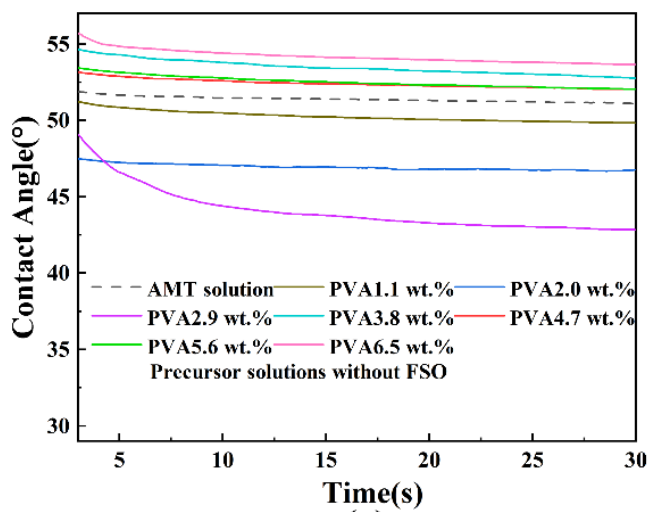

(a)

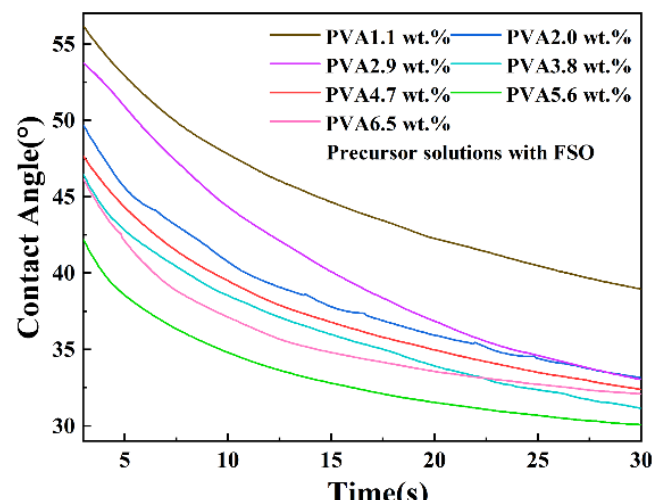

(b)

Figure 3. Ammonium meta-tungstate (AMT) solution and the precursor solutions: (a) relationship between contact angle and time without 2-perfluoroalkyl ethanol (FSO), (b) relationship between contact angle and time with FSO.

Films printed using AMT solution and the precursor solutions without FSO were observed under an optical microscope at $10 \times$ magnification in Figure $4 a-h$, which showed the effect of the dynamic viscosity on film formation. AMT had high solubility in water, but there was polycrystal of the films in Figure 4a and the polycrystal was ammonium para-tungstate (APT) according to the XRD analysis (Figure 6a). It was found by comparing Figure $4 a-d$ and that the addition of PVA could improve the uniformity of the film. One possible reason was that the increase in PVA molecules separated the APT molecules in space. Another possible reason given by a previous study was that hydrogen bonds of $\mathrm{NH}_{4}{ }^{+}$ions with $-\mathrm{OH}$ groups of PVA [37] separated APT, which was beneficial to improve the uniformity of the film. The films in Figure $4 \mathrm{a}-\mathrm{d}$ were uneven because of the low dynamic viscosity. It was illustrated by comparing the films in Figure $4 \mathrm{e}-\mathrm{l}$ and Figure $4 \mathrm{a}-\mathrm{d}$ that the film uniformity was greatly improved when the dynamic viscosity ranged from $16.27 \mathrm{mPa} \cdot \mathrm{s}$ to $163.61 \mathrm{mPa} \cdot \mathrm{s}$.

Films printed using the precursor solutions at $3.8 \mathrm{wt} . \%, 4.7 \mathrm{wt} . \%, 5.6 \mathrm{wt} . \%$ and $6.5 \mathrm{wt} . \%$ PVA without FSO and with FSO were observed under an optical microscope at $10 \times$ magnification as shown in Figure $4 \mathrm{e}-\mathrm{h}$ and Figure $4 \mathrm{i}-\mathrm{l}$, respectively. The films are still uneven in Figure $4 \mathrm{e}-\mathrm{h}$ because there were holes in the films. From Figure $4 \mathrm{a}$, the entire contact angle curves of the precursor solutions without FSO at $3.8 \mathrm{wt} . \%, 4.7 \mathrm{wt} . \%, 5.6 \mathrm{wt} . \%$ and $6.5 \mathrm{wt} . \%$ PVA were higher than that of AMT solution, proving that unsatisfactory film formation was due to the poor wettability. Comparing Figure $4 \mathrm{i}-1$ with Figure $4 \mathrm{e}-\mathrm{h}$, it is indicated that at the same mass fraction of PVA, the addition of FSO could help film formation by improving the wettability of the precursor solutions on the ITO substrate. The films in Figure 4i-1 had relatively smooth surfaces compared with the films in Figure $4 \mathrm{a}-\mathrm{h}$, which illustrates that films formed fine when the surface tension ranged from $16.17 \mathrm{mN} / \mathrm{m}$ to $22.90 \mathrm{mN} / \mathrm{m}$ and the dynamic viscosity ranged from $28.40 \mathrm{mPa} \cdot \mathrm{s}$ to $163.61 \mathrm{mPa} \cdot \mathrm{s}$. 


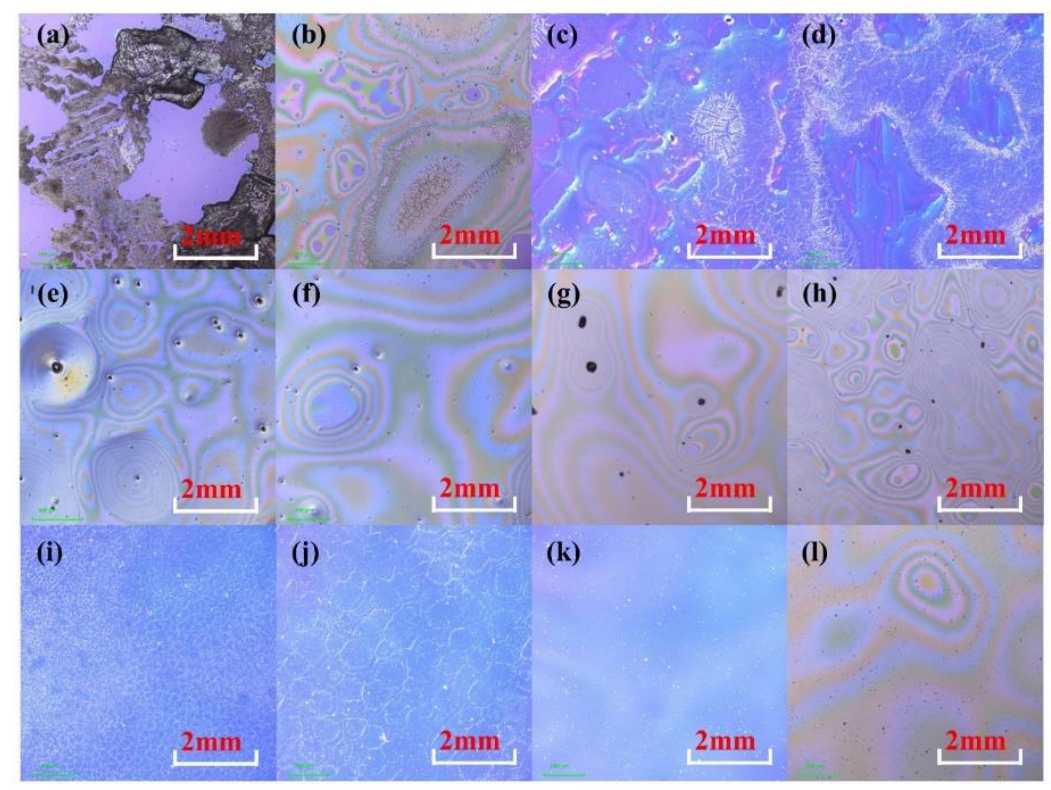

Figure 4. Screen printing films by different solutions: (a) AMT solution without polyvinyl alcohol (PVA) and FSO, (b) with 1.1 wt.\% PVA, (c) with 2.0 wt.\% PVA, (d) with 2.9 wt.\% PVA, (e) with 3.8 wt.\% PVA, (f) with 4.7 wt.\% PVA, (g) with 5.6 wt.\% PVA, (h) with 6.5 wt.\% PVA, (i)with 3.8 wt.\% PVA + 0.013 wt. $\%$ FSO, (j) with 4.7 wt. $\%$ PVA + 0.016 wt. $\%$ FSO, (k) with 5.6 wt. $\%$ PVA + 0.019 wt. $\%$ FSO, (1) with 6.5 wt. \% PVA + 0.022 wt. \% FSO.

The precursor solutions for the films shown in Figure 4i-l were suitable for screen printing, so for convenient description, the term 'ink formulas' was used to refer to the precursor solutions adding $3.8 \mathrm{wt} . \%, 4.7 \mathrm{wt} . \%, 5.6 \mathrm{wt} . \%$ and $6.5 \mathrm{wt} . \%$ PVA with, respectively, 0.013 wt. $\%, 0.016$ wt. $\%, 0.019$ wt. $\%$ and 0.022 wt. $\%$ FSO in the next part of this study. The ink formulas are universal in some areas, which means that some other types of film can be screen-printed by replacing AMT with other material and then adjusting it slightly.

\subsection{Effect of Annealing on Composition and Transmittance of Films}

Having defined what was meant by 'ink formulas', the effect of annealing on the films will be discussed. The FT-IR spectra of unannealed films printed with the ink formulas are shown in Figure 5a. In Figure 5a, the infrared absorption at $3240 \mathrm{~cm}^{-1}, 2947 \mathrm{~cm}^{-1}$ and $1087 \mathrm{~cm}^{-1}$ can be, respectively, assigned to tensile vibration mode of $-\mathrm{OH},-\mathrm{CH}_{2}$ and $\mathrm{C}-\mathrm{O}$ in PVA [38]. There was still a little water in unannealed films because the absorption at $1630 \mathrm{~cm}^{-1}$ in Figure $5 \mathrm{a}$ was caused by the tensile vibration mode of $\mathrm{H}-\mathrm{O}-\mathrm{H}$ [39]. The infrared absorption at $3427 \mathrm{~cm}^{-1}$ corresponded to the characteristic $\mathrm{N}-\mathrm{H}$ stretching [40]. According to the XRD analysis in Figure $6 \mathrm{a}, \mathrm{N}-\mathrm{H}$ stretching existed in APT. The FT-IR spectra of annealed films printed with the ink formulas are shown in Figure 5b. Comparing Figure $5 b$ with Figure $5 a$, it is found that PVA and water in the films were greatly reduced due to annealing. Figure $5 \mathrm{c}$ was an enlargement in the $1050-800 \mathrm{~cm}^{-1}$ wavenumber range of Figure 5 b. From Figure $5 c$, the bands at $900-600 \mathrm{~cm}^{-1}$ and $990-960 \mathrm{~cm}^{-1}$ are, respectively, attributed to $\mathrm{W}-\mathrm{O}-\mathrm{W}$ stretching vibration and $\mathrm{W}=\mathrm{O}$ stretching vibration, which illustrated all the annealed films contained $\mathrm{WO}_{3}$ [41]. 


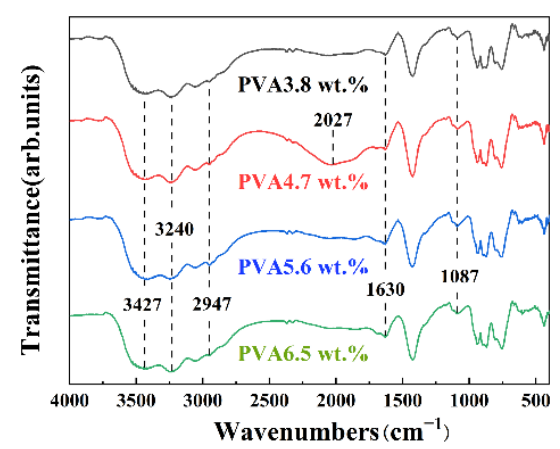

(a)

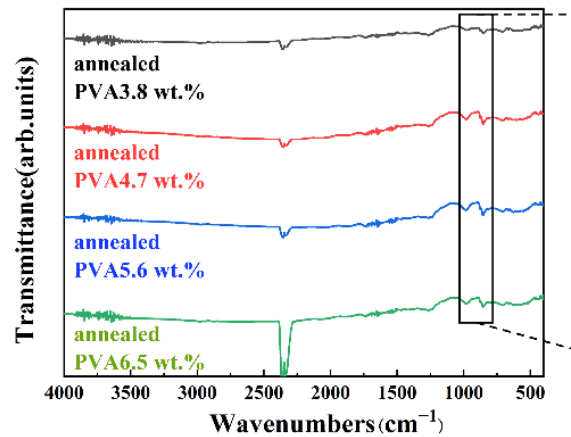

(b)

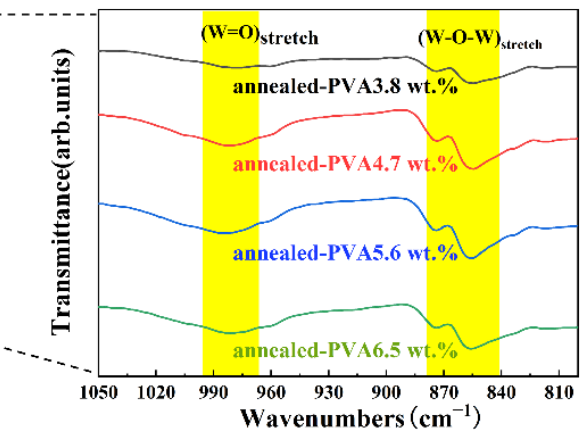

(c)

Figure 5. Fourier transform infrared (FT-IR) spectra of films: (a) screen printing PVA + FSO ink formulas without annealing process, (b) screen printing PVA + FSO ink formulas with annealing process, (c) enlargement in 1050-800 $\mathrm{cm}^{-1}$ wavenumber range.

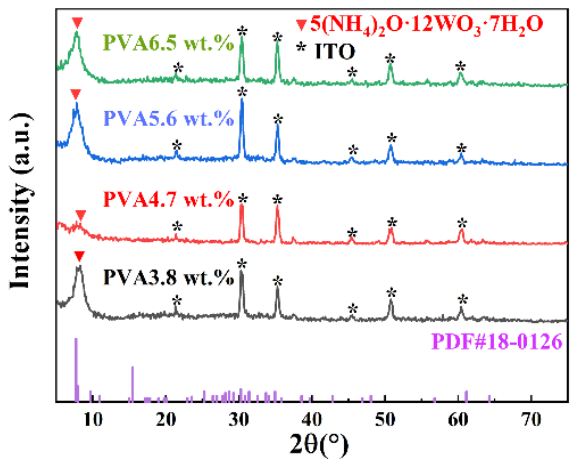

(a)

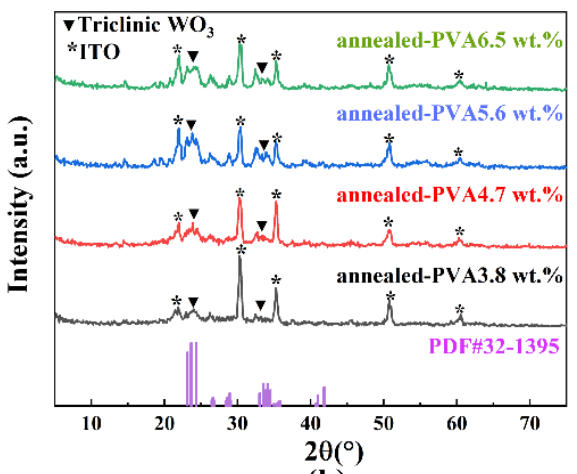

(b)

Figure 6. X-ray diffraction (XRD) patterns of films: (a) screen printing PVA + FSO ink formulas without annealing process, (b) screen printing PVA + FSO ink formulas with annealing process.

The XRD patterns in Figure 6 were analyzed using the software Jade 6.0, PDF \#180126(5 $\left.\left(\mathrm{NH}_{4}\right)_{2} \mathrm{O} \cdot 12 \mathrm{WO}_{3} \cdot 7 \mathrm{H}_{2} \mathrm{O}\right)$ and PDF \#32-1395(triclinic $\mathrm{WO}_{3}$ ). The XRD patterns of unannealed films printed with the ink formulas are shown in Figure 6a. From Figure 6a, the polycrystal in all the unannealed films was $5\left(\mathrm{NH}_{4}\right)_{2} \mathrm{O} \cdot 12 \mathrm{WO}_{3} \cdot 7 \mathrm{H}_{2} \mathrm{O}$, which is a kind of ammonium para-tungstate (APT) crystal. A probable explanation was that AMT was converted into APT during the printing and drying process. The XRD patterns of annealed films printed with the ink formulas are shown in Figure $6 \mathrm{~b}$. From Figure $6 \mathrm{~b}$, triclinic $\mathrm{WO}_{3}$ was found in all the annealed films. It can also be qualitatively observed in Figure $6 \mathrm{~b}$ that the crystallinity of triclinic $\mathrm{WO}_{3}$ increased and then decreased with the increase of PVA mass fraction while obtaining the highest crystallinity at $5.6 \mathrm{wt}$ \% PVA. The reason might be that the mass fraction and entanglement of PVA affected the thermal decomposition of 
APT in the annealing process. Comparing Figure $6 a$ with Figure $6 \mathrm{~b}$, it can be illustrated that $\mathrm{WO}_{3}$ is generated from APT decomposition in the annealing process.

It can be found in Figures 5 and 6 that annealing removed PVA and produced $\mathrm{WO}_{3}$, proving that annealing was an effective post-treatment for the films screen-printed with the ink formulas. The unannealed film containing $4.7 \mathrm{wt} . \%$ PVA was special. From Figure $5 \mathrm{a}$, there was a very wide absorption peak around $2027 \mathrm{~cm}^{-2}$, which was assigned to stretching vibration of $\mathrm{C} \equiv \mathrm{N}$ and $\mathrm{C} \equiv \mathrm{C}$. From Figure $6 \mathrm{a}$, the film containing $4.7 \mathrm{wt.} \%$ PVA had little polycrystal. A possible explanation was that PVA formed a special physical structure by accidental entanglement, which led to the unexpected infrared absorption peak and polycrystal inhibition.

Figure 7a shows the transmittance of unannealed films printed with the ink formulas. It was found in Figure $7 \mathrm{a}$ that transmittance increased with the increased mass fraction of PVA. A possible explanation is that the PVA molecules tended to aggregate with the increase of PVA mass fraction because the concentration exceeded the CMC, making the film more transparent. Figure $7 \mathrm{~b}$ shows the transmittance of annealed films printed with the ink formulas. The thickness of the annealed films at $3.8 \mathrm{wt} . \%, 4.7 \mathrm{wt} . \%, 5.6 \mathrm{wt} . \%$ and $6.5 \mathrm{wt} . \%$ PVA were, respectively, $486.2 \mathrm{~nm}, 458.8 \mathrm{~nm}, 580.7 \mathrm{~nm}$ and $426.8 \mathrm{~nm}$. For the annealed films, the transmittance in Figure $7 \mathrm{~b}$ decreased with the increased film thickness. Comparing Figure $7 \mathrm{~b}$ with Figure $7 \mathrm{a}$, it was found that at the same fraction of PVA, the transmittance of the annealed films was overall higher than that of unannealed films because PVA and water were removed.

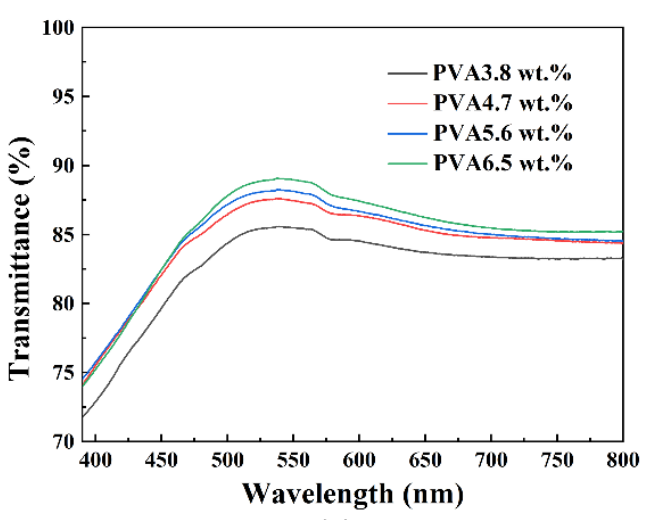

(a)

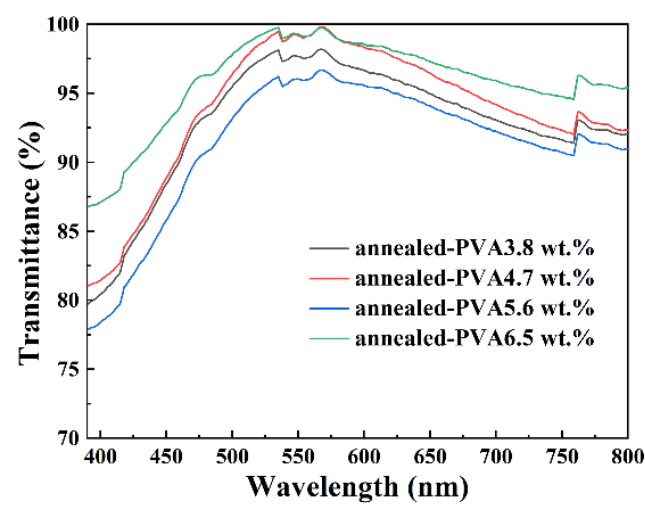

(b)

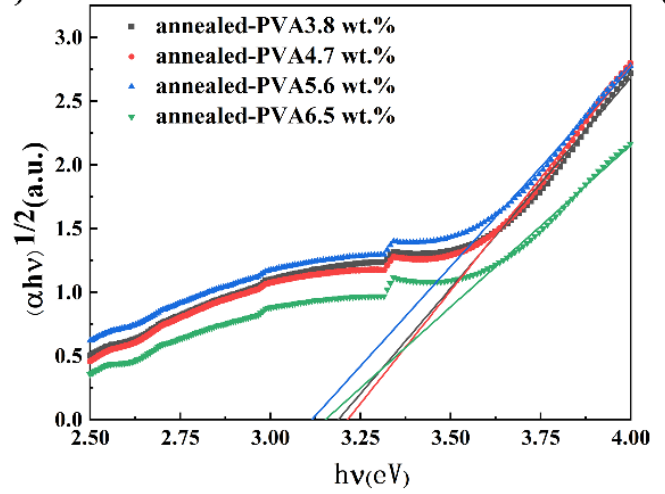

(c)

Figure 7. Transmittance of films: (a) screen printing PVA + FSO ink formulas without annealing process, (b) screen printing PVA + FSO ink formulas with annealing process, (c) optical bandgap energy of annealed films using the ink formulas.

Figure $7 \mathrm{c}$ shows the optical bandgap energy of the annealed films. According to the Formula (2) [42]:

$$
(\alpha \mathrm{h} v)=\mathrm{A}(\mathrm{h} v-\mathrm{Eg})^{\mathrm{n}}
$$


where $\alpha$ is the absorption coefficient of the films; $h$ is the Planck constant; $v$ is light frequency; $\mathrm{A}$ is a constant; $\mathrm{n}=2$ because tungsten oxide belongs to the indirect bandgap and Eg is the optical bandgap which is the value of the fitting line horizontal intercept of $(\alpha \mathrm{h} v)^{1 / 2}$ versus the photon energy $\mathrm{h} v$. It can be obtained from Figure $7 \mathrm{c}$ that the band gaps of the annealed films printed with the ink formulas at $3.8 \mathrm{wt} . \%, 4.7 \mathrm{wt} . \%, 5.6 \mathrm{wt} . \%$ and $6.5 \mathrm{wt} . \%$ PVA were $3.18 \mathrm{eV}, 3.21 \mathrm{eV}, 3.12 \mathrm{eV}$ and $3.15 \mathrm{eV}$, respectively, which were all in the normal range of the $\mathrm{WO}_{3}$ bandgap.

\subsection{Electrochromic Performance}

For the performance of Figure 8, the applied voltage cycle consisted of $-3 \mathrm{~V}$ for $15 \mathrm{~s}$ and $3 \mathrm{~V}$ for $15 \mathrm{~s}$. Figure 8a shows the relation of current with the time of the annealed films printed with the ink formulas. The injecting and extracting charges per unit area $(\Delta Q)$ were calculated based on the current of a cycle of electrochromic test. It was found in Figure 8a that $\Delta \mathrm{Q}$ first decreased and then increased with the increase PVA mass fraction while obtaining the minimum at $5.6 \mathrm{wt} . \%$ PVA. From Figure $8 \mathrm{~b}$, the crystallinity of triclinic WO3 increased and then decreased with the increase PVA mass fraction while obtaining the highest crystallinity at $5.6 \mathrm{wt} . \%$ PVA. We all know that the electrochromic mechanism refers to a process of electron and $\mathrm{Li}^{+}$migration [43], so $\mathrm{Li}^{+}$migration can affect the $\Delta \mathrm{Q}$. Therefore, a possible explanation provided by several studies for the relation of the crystallinity and $\Delta \mathrm{Q}$ was that the increase of crystallinity made it more difficult for $\mathrm{Li}^{+}$to disengage and embed [44-46].

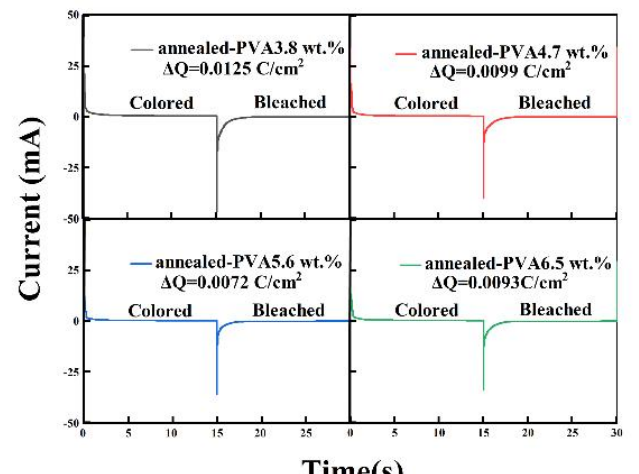

(a)

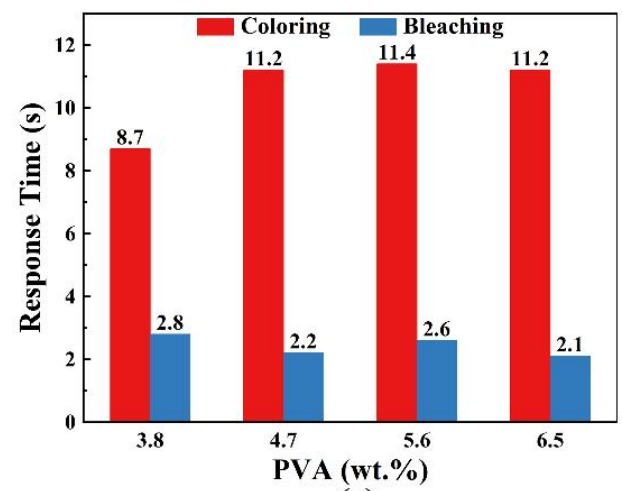

(c)

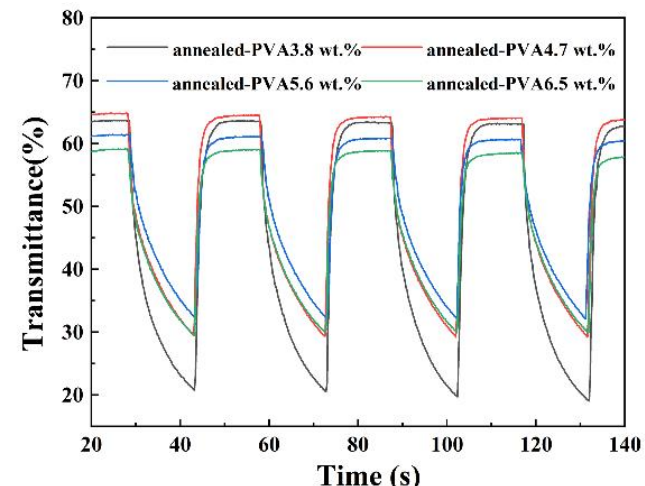

(b)

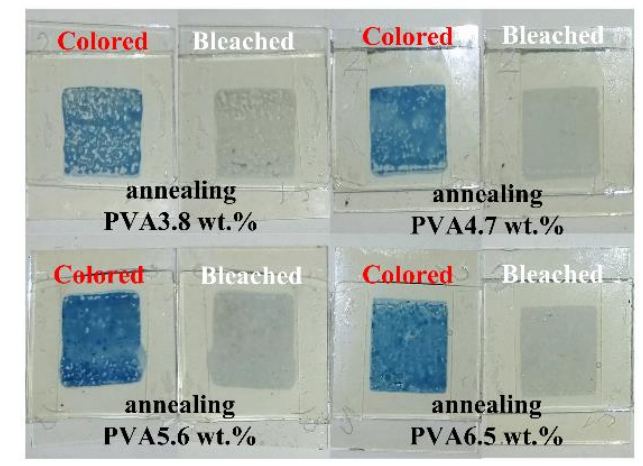

(d)

Figure 8. Optoelectronic character of annealed films using the different ink formulas: (a) relationship between current and time in one cycle, (b) relationship between transmittance and time, (c) the coloring/bleaching response time, (d) the device photo images. (at $600 \mathrm{~nm}$ wavelength).

Figure $8 \mathrm{~b}$ shows the optical transmittance spectra at $600 \mathrm{~nm}$ of the annealed films printed with the ink formulas. The optical modulation of the device was defined as the difference between the highest and lowest transmittances. It is shown in Figure $8 \mathrm{~b}$ that 
optical modulation of the annealed films decreased one by 1 at 3.8 wt. $\%, 4.7$ wt. $\%$ and $5.6 \mathrm{wt} . \%$ PVA while there was little difference on the optical modulation of the annealed films at $5.6 \mathrm{wt} . \%$ and $6.5 \mathrm{wt} . \%$ PVA. One reason was that crystallinity affected $\mathrm{Li}^{+}$migration, resulting in the decrease of the optical modulation. The other possible reason was that the residues from PVA thermal decomposition affected the number of electrons involved in the electrochromic reaction, which led to the electron injection of the film at $5.6 \mathrm{wt} . \%$ PVA being smaller than that of the film at $6.5 \mathrm{wt}$ \% PVA but there was little difference in the optical modulations.

The time required for the device from the highest optical transmittance to the transmittance dropping by $90 \%$ of the optical modulation is recorded as the coloring response time while the time required from the lowest optical transmittance to the transmittance increasing by $90 \%$ of the optical modulation is recorded as the fading response time. Figure $8 \mathrm{c}$ showed the coloring and bleaching response time in the same cycle of the annealed films printed with the ink formulas. It was found in Figure 8c that the coloring response time first increased and then decreased with the increase in PVA mass fraction while obtaining a minimum at $3.8 \mathrm{wt} . \%$ PVA. It might be explained that that crystallinity affected $\mathrm{Li}^{+}$ migration, resulting in the change of the response time. Figure $8 \mathrm{c}$ also illustrates that the bleaching was almost complete within $3 \mathrm{~s}$ for all the annealed films. This implied that these films showed a relatively fast bleaching response, which might be due to the pores introduced by PVA thermal decomposition [47]. Figure 8d shows the colored and bleached states of the electrochromic devices, demonstrating that the annealed films screen-printed with the ink formulas could complete the electrochromic function.

Figure 9 indicates the electrochromic performance of the annealed film printed with the ink formula at $3.8 \mathrm{wt}$ \% PVA had the best optical modulation and the shortest coloring response time. The transmittance of the initial state, colored state, and bleached state of the film is shown in Figure 9a. In Figure 9a, it is shown that the blue color of the device in the colored state was due to the good absorption of long wavelengths in the visible light region. It can also be proved in Figure 9a that the device had stronger absorption in the infrared region, which stated that the film could absorb heat.

It can be seen in Figure $8 \mathrm{~b}$ that the transmittance continued to decrease in the coloring process. To make the transmittance of the coloring device reach a stable value, the measurement conditions were changed. The applied voltage of response time of the film at $600 \mathrm{~nm}$ in Figure $9 \mathrm{~b}$ was $-3 \mathrm{~V}$ for $240 \mathrm{~s}$ and then $3 \mathrm{~V}$ for $240 \mathrm{~s}$ for one cycle. From Figure $9 \mathrm{~b}$, the coloring response time was $87.5 \mathrm{~s}$ and the bleaching response time was $18.5 \mathrm{~s}$. It can be seen in Figure $9 b$ that the optical transmittance of the film still continued to decrease if the charge was injected for a long time, which proved that the film could have large optical modulation with sufficient charge injection. The long coloring response time might be caused by the low electrical conductivity of $\mathrm{WO}_{3}$, which could be solved by embedding silver nanowire [48].

The optical density (OD) in Figure $9 \mathrm{c}$ is characterized as under $1.01 \times 10^{-5} \mathrm{~A} \cdot \mathrm{cm}^{-2}$ constant current density. Coloration efficiency (CE) is also an important parameter to evaluate electrochromic performance, which is defined by the following Equations (3) and (4) $[49,50]:$

$$
\begin{aligned}
\mathrm{CE}=\Delta \mathrm{OD} / \Delta \mathrm{Q} & =\log \left(\mathrm{T}_{\mathrm{b}} / \mathrm{T}_{\mathrm{c}}\right) /(\mathrm{Q} / \mathrm{A}) \\
\mathrm{Q} & =\int \mathrm{Idt}
\end{aligned}
$$

In the Equation (2), $\triangle \mathrm{OD}$ is the optical density of the change between two optical states at $600 \mathrm{~nm}$ wavelength; $\mathrm{Tb}$ and Tc were the points from the optical transmittance curve; the injecting and extracting charge density (Q) was calculated by integrating the current injected and $\mathrm{A}$ is $1 \mathrm{~cm}^{-2}$ as the electrochromic total area. It was found in Figure $9 \mathrm{c}$ that the $C E$ of the film could attain $93.25 \mathrm{~cm}^{-2} \cdot \mathrm{C}^{-1}$. 


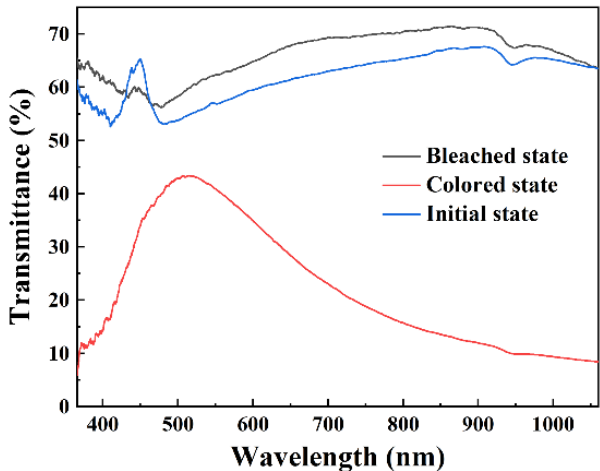

(a)

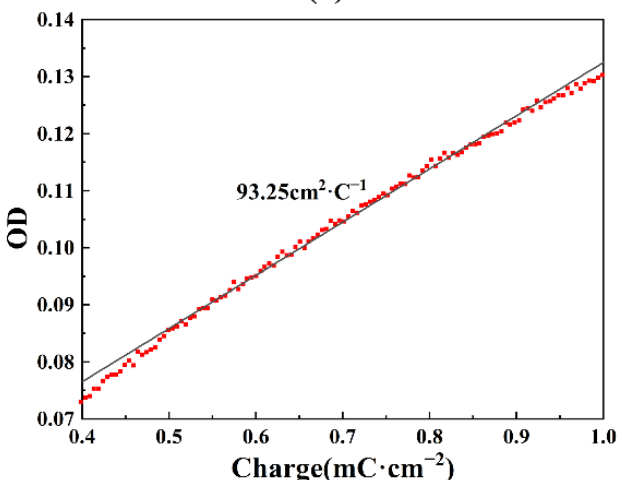

(c)

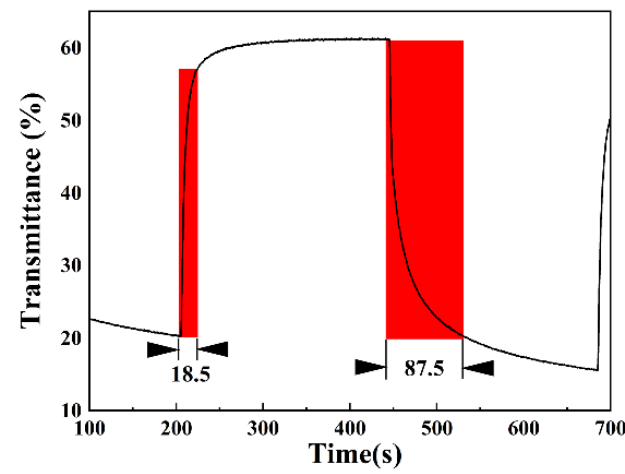

(b)

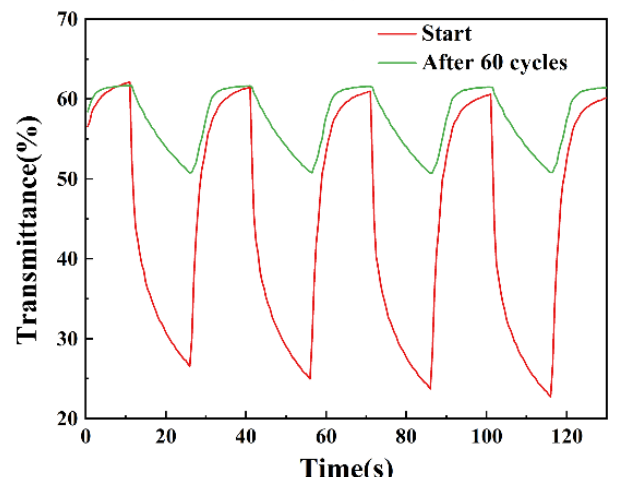

(d)

Figure 9. Properties of the annealed film using $3.8 \mathrm{wt}$ \% PVA ink formulas: (a) optical transmittance spectra in initial, bleached and colored state, (b) response time, (c) optical density, (d) transmittance at the start and after 60 cycles (at $600 \mathrm{~nm}$ wavelength).

The optical transmittance spectra at the start and after 60 cycles at $600 \mathrm{~nm}$ in Figure $9 \mathrm{~d}$ under applied voltage cycle consisted of $-3 \mathrm{~V}$ for $15 \mathrm{~s}$ and $3 \mathrm{~V}$ for $15 \mathrm{~s}$. it is shown in Figure $9 \mathrm{~d}$ that the stability of the film was not very good because the optical modulation had a $25.80 \%$ decline after 60 cycles. One reason might be that the annealed films were composed of polycrystals (Figure 6b) but generally $\mathrm{WO}_{3}$ crystal films had better stability because of the stable structure [51]. Another possible reason was that PVA thermal decomposition produced residues and pores (Figure 8d), which might affect significantly the stability of the films under the applied voltage cycles. The stability might be improved by modifying the precursor solutions and changing the annealing method.

\section{Conclusions}

In this study, $\mathrm{WO}_{3}$ electrochromic film was successfully prepared by screen printing. Polyvinyl alcohol (PVA) and 2-perfluoroalkyl ethanol (FSO) were added to modify the precursor solutions. The addition of PVA improved the dynamic viscosity of the precursor solutions and modify the uniformity of the films. FSO improved the wettability of the precursor solutions by decreasing the surface tension. The precursor solutions with dynamic viscosity in the range of $28.40 \mathrm{mPa} \cdot \mathrm{s}$ to $163.61 \mathrm{mPa} \cdot \mathrm{s}$ and surface tension in the range of $16.17 \mathrm{mN} / \mathrm{m}$ to $22.90 \mathrm{mN} / \mathrm{m}$ formed film well on the ITO substrate. The ink formulas that were the precursor solutions adding $3.8 \mathrm{wt} \%$, $4.7 \mathrm{wt} . \%, 5.6 \mathrm{wt} \%$ and $6.5 \mathrm{wt}$ \% PVA with, respectively, 0.013 wt. $\%, 0.016$ wt. $\%, 0.019$ wt. $\%$ and 0.022 wt. $\%$ FSO are universal in some areas, which makes sense in the preparation of other types of functional films by screen printing. The annealing removed PVA, produced $\mathrm{WO}_{3}$ and improved the transmittance of the film. The optical modulation of the film was affected by crystallinity and residues of PVA thermal decomposition. It was found that the ink formulas with $3.8 \mathrm{wt}$ \% PVA and $0.013 \mathrm{wt} . \%$ FSO had the best performance in this work. The coloration efficiency of the film could attain $93.25 \mathrm{~cm}^{-2} \cdot \mathrm{C}^{-1}$ but the stability of the film required improvement. 
In this study, the screen-printing inks were prepared and $\mathrm{WO}_{3}$ electrochromic films were obtained through annealing, which had positive significance in the preparation of $\mathrm{WO}_{3}$ electrochromic devices by the low-cost screen-printing method.

Author Contributions: Conceptualization, K.G. and G.Z.; Methodology, K.G.; Funding acquisition, H.N., R.Y. and J.P.; Validation, G.Z.; Formal analysis, K.G.; Investigation, K.G. and G.Z.; Resources, R.Y. and J.P.; Data Curation, K.G.; Writing—Original Draft, K.G.; Writing—Review and Editing, Y.L., H.N., Z.X., T.Q., D.L., M.L. and J.P.; Visualization, K.G. and G.Z.; Supervision, H.N. and R.Y.; Project administration, H.N., R.Y. and J.P. All authors have read and agreed to the published version of the manuscript.

Funding: This work was supported by Key-Area Research and Development Program of Guangdong Province (No.2020B010183002), National Natural Science Foundation of China (Grant No.62074059 and 22090024), Guangdong Major Project of Basic and Applied Basic Research (No.2019B030302007), Guangdong Basic and Applied Basic Research Foundation (Grant No.2020B1515020032), Fundamental Research Funds for the Central Universities (No.2020ZYGXZR060), Ji Hua Laboratory scientific research project (X190221TF191), South China University of Technology 100 Step Ladder Climbing Plan Research Project (No.j2tw202102000) and 2021 Guangdong University Student Science and Technology Innovation Special Fund (“Climbing Plan” Special Fund) (No.pdjh2021b0036).

Acknowledgments: We thank Xingci Lu for his administrative support during the preparation of this manuscript.

Conflicts of Interest: The authors declare no conflict of interest.

\section{References}

1. Wu, M.; Shi, Y.; Li, R.; Wang, P. Spectrally selective smart window with high near-infrared light shielding and controllable visible light transmittance. ACS Appl. Mater. Interfaces 2018, 10, 39819-39827. [CrossRef]

2. Wang, Z.; Zhu, M.; Gou, S.; Pang, Z.; Wang, Y.; Su, Y.; Huang, Y.; Weng, Q.; Schmidt, O.G.; Xu, J. Pairing of luminescent switch with electrochromism for quasi-solid-state dual-function smart windows. ACS Appl. Mater. Interfaces 2018, 10, 31697-31703. [CrossRef] [PubMed]

3. Kim, J.-H.; Hong, J.; Han, S.-H. Optimized physical properties of electrochromic smart windows to reduce cooling and heating loads of office buildings. Sustainability 2021, 13, 1815. [CrossRef]

4. Ke, Y.; Chen, J.; Lin, G.; Wang, S.; Zhou, Y.; Yin, J.; Lee, P.S.; Long, Y. Smart windows: Electro-, thermo-, mechano-, photochromics, and beyond. Adv. Eng. Mater. 2019, 9, 1902066. [CrossRef]

5. Cai, G.; Eh, A.L.-S.; Ji, L.; Lee, P.S. Recent advances in electrochromic smart fenestration. Adv. Sustain. Syst. 2017, 1, 1700074. [CrossRef]

6. Li, H.; McRae, L.; Firby, C.J.; Elezzabi, A.Y. Rechargeable aqueous electrochromic batteries utilizing Ti-substituted tungsten molybdenum oxide based $\mathrm{Zn}^{2+}$ ion intercalation cathodes. Adv. Mater. 2019, 31, e1807065. [CrossRef] [PubMed]

7. Celiesiute, R.; Ramanaviciene, A.; Gicevicius, M.; Ramanavicius, A. Electrochromic sensors based on conducting polymers, metal oxides, and coordination complexes. Crit. Rev. Anal. Chem. 2019, 49, 195-208. [CrossRef] [PubMed]

8. Wu, W.; Wang, M.; Ma, J.; Cao, Y.; Deng, Y. Electrochromic metal oxides: Recent progress and prospect. Adv. Electron. Mater. 2018, 4, 1800185. [CrossRef]

9. Wang, Z.; Wang, $\mathrm{H} . ; \mathrm{Gu}, \mathrm{X}$; $\mathrm{Cui}, \mathrm{H} .-\mathrm{N}$. Hierarchical structure $\mathrm{WO}_{3} / \mathrm{TiO}_{2}$ complex film with enhanced electrochromic performance. Solid State Ionics 2019, 338, 168-176. [CrossRef]

10. Tang, C.-J.; He, J.-L.; Jaing, C.-C.; Liang, C.-J.; Chou, C.-H.; Han, C.-Y.; Tien, C.-L. An all-solid-state electrochromic device based on $\mathrm{WO}_{3}-\mathrm{Nb}_{2} \mathrm{O}_{5}$ composite films prepared by fast-alternating bipolar-pulsed reactive magnetron sputtering. Coatings 2019, 9, 9. [CrossRef]

11. Zhang, X.P.; Zhang, H.K.; Li, Q.; Luo, H.L. An all-solid-state inorganic electrochromic display of $\mathrm{WO}_{3}$ and $\mathrm{NiO}$ films with $\mathrm{LiNbO}_{3}$ ion conductor. IEEE Electron. Device Lett. 2000, 21, 215-217. [CrossRef]

12. Chen, H.-C.; Jan, D.-J.; Chen, C.-H. Investigation of optical and electrochromic properties of tungsten oxide deposited with horizontal DC and DC pulse magnetron sputtering. Jpn. J. Appl. Phys. 2012, 51, 045503. [CrossRef]

13. Tajima, K.; Watanabe, H.; Nishino, M.; Kawamoto, T. Electrochromic properties of $\mathrm{WO}_{3}$ thin films fabricated by magnetron sputtering, ion plating, and spin coating: A comparative investigation. J. Ceram. Soc. Jpn. 2020, 128, 381-386. [CrossRef]

14. Zhang, G.; Lu, K.; Zhang, X.; Yuan, W.; Shi, M.; Ning, H.; Tao, R.; Liu, X.; Yao, R.; Peng, J. Effects of annealing temperature on optical band gap of sol-gel tungsten trioxide films. Micromachines 2018, 9, 377. [CrossRef]

15. Zhang, G.; Lu, K.; Zhang, X.; Yuan, W.; Ning, H.; Tao, R.; Liu, X.; Yao, R.; Peng, J. Enhanced transmittance modulation of $\mathrm{SiO}$-doped crystalline $\mathrm{WO}_{3}$ films prepared from a polyethylene oxide (PEO) template. Coatings 2018, 8, 228. [CrossRef]

16. Shi, M.; Qiu, T.; Tang, B.; Zhang, G.; Yao, R.; Xu, W.; Chen, J.; Fu, X.; Ning, H.; Peng, J. Temperature-controlled crystal size of wide band gap nickel oxide and its application in electrochromism. Micromachines 2021, 12, 80. [CrossRef] [PubMed]

17. Kadam, A.V.; Bhosale, N.Y.; Patil, S.B.; Mali, S.S.; Hong, C.K. Fabrication of an electrochromic device by using $\mathrm{WO}_{3}$ thin films synthesized using facile single-step hydrothermal process. Thin Solid Films 2019, 673, 86-93. [CrossRef] 
18. Pan, J.; Wang, Y.; Zheng, R.; Wang, M.; Wan, Z.; Jia, C.; Weng, X.; Xie, J.; Deng, L. Directly grown high-performance WO 3 films by a novel one-step hydrothermal method with significantly improved stability for electrochromic applications. J. Mater. Chem. A 2019, 7, 13956-13967. [CrossRef]

19. Varghese, T.; Dun, C.; Kempf, N.; Saeidi-Javash, M.; Karthik, C.; Richardson, J.; Hollar, C.; Estrada, D.; Zhang, Y. Flexible thermoelectric devices of ultrahigh power factor by scalable printing and interface engineering. Adv. Funct. Mater. 2019, 30, 1905796. [CrossRef]

20. Limmanee, A.; Krudtad, P.; Songtrai, S.; Jaroensathainchok, S.; Krajangsang, T.; Sritharathikhun, J.; Sriprapha, K. MOCVD ZnO/screen printed Ag back reflector for flexible thin film silicon solar cell application. Int. J. Photoenergy 2014, 2014, 1-7. [CrossRef]

21. Li, D.; Liu, X.; Chen, X.; Lai, W.Y.; Huang, W. A simple strategy towards highly conductive silver-nanowire inks for screen-printed flexible transparent conductive films and wearable energy-storage devices. Adv. Mater. Technol. 2019, 4, 1900196. [CrossRef]

22. Hu, J.; Guo, H.; Li, C.-J.; Zhang, Y.-C.; Yuan, J.-X.; Zhang, S.-S.; Zhao, L.-L. Preparation and discharge performance of thin-film thermal battery. Energy Technol. 2020, 8, 2000737. [CrossRef]

23. Duan, S.; Gao, X.; Wang, Y.; Yang, F.; Chen, M.; Zhang, X.; Ren, X.; Hu, W. Scalable fabrication of highly crystalline organic semiconductor thin film by channel-restricted screen printing toward the low-cost fabrication of high-performance transistor arrays. Adv. Mater. 2019, 31, e1807975. [CrossRef] [PubMed]

24. Wang, L.-L.; Tay, B.-K.; See, K.-Y.; Sun, Z.; Tan, L.-K.; Lua, D. Electromagnetic interference shielding effectiveness of carbon-based materials prepared by screen printing. Carbon 2009, 47, 1905-1910. [CrossRef]

25. Sánchez, M.; Rincón, M.E. Sensor response of sol-gel multiwalled carbon nanotubes- $\mathrm{TiO}_{2}$ composites deposited by screen-printing and dip-coating techniques. Sens. Actuators B Chem. 2009, 140, 17-23. [CrossRef]

26. Santiago, S.; Aller, M.; Campo, F.J.; Guirado, G. Screen-printable electrochromic polymer inks and ion gel electrolytes for the design of low-power, flexible electrochromic devices. Electroanalysis 2019, 31, 1664-1671. [CrossRef]

27. Krebs, F.C. Fabrication and processing of polymer solar cells: A review of printing and coating techniques. Sol. Energy Mater. Sol. Cells 2009, 93, 394-412. [CrossRef]

28. Baharuddin, N.A.; Abdul Rahman, N.F.; Rahman, H.A.; Somalu, M.R.; Azmi, M.A.; Raharjo, J. Fabrication of high-quality electrode films for solid oxide fuel cell by screen printing: A review on important processing parameters. Int. J. Energy Res. 2020, 44, 8296-8313. [CrossRef]

29. Ma, Q.; Du, L.; Yang, Y.; Wang, L. Rheology of film-forming solutions and physical properties of tara gum film reinforced with polyvinyl alcohol (PVA). Food Hydrocoll. 2017, 63, 677-684. [CrossRef]

30. Shimizu, Y.; Tanabe, T.; Yoshida, H.; Kasuya, M.; Matsunaga, T.; Haga, Y.; Kurihara, K.; Ohta, M. Viscosity measurement of Xanthan-Poly(vinyl alcohol) mixture and its effect on the mechanical properties of the hydrogel for 3D modeling. Sci. Rep. 2018, 8, 16538. [CrossRef] [PubMed]

31. Yang, H.; Xu, S.; Jiang, L.; Dan, Y. Thermal decomposition behavior of poly (vinyl alcohol) with different hydroxyl content. J. Macromol. Sci. Part B 2011, 51, 464-480. [CrossRef]

32. Hunyadi, D.; Sajó, I.; Szilágyi, I.M. Structure and thermal decomposition of ammonium metatungstate. J. Therm. Anal. Calorim. 2013, 116, 329-337. [CrossRef]

33. French, G.J.; Sale, F.R. A re-investigation of the thermal decomposition of ammonium paratungstate. J. Mater. Sci. 1981, 16, 3427-3436. [CrossRef]

34. Li, G.-H.; Cho, C.-G. Synthesis and micellar behavior of poly(vinyl alcohol-b-styrene) copolymers containing PVA blocks with different syndiotacticity. Colloid. Polym. Sci. 2004, 283, 946-953. [CrossRef]

35. Li, G.H.; Cho, C.G. CMC and dynamic properties of poly(VA-b-St) copolymer micelles for drug delivery. Korean J. Chem. Eng. 2008, 25, 1444-1447. [CrossRef]

36. Wang, L.; Tiu, C.; Liu, T.J. Effects on nonionic surfactant and associative thickener on the rheology of polyacrylamide in aqueous glycerol solutions. Colloid. Polym. Sci. 1996, 274, 138-144. [CrossRef]

37. Tretinnikov, O.N.; Zagorskaya, S.A. Effect of inorganic salts on the crystallinity of polyvinyl alcohol. J. Appl. Spectrosc. 2012, 78, 904-908. [CrossRef]

38. Karimi, A.; Wan Daud, W.M.A. Materials, preparation, and characterization of PVA/MMT nanocomposite hydrogels: A review. Polym. Compos. 2015, 38, 1086-1102. [CrossRef]

39. Asad, M.; Saba, N.; Asiri, A.M.; Jawaid, M.; Indarti, E.; Wanrosli, W.D. Preparation and characterization of nanocomposite films from oil palm pulp nanocellulose/poly (Vinyl alcohol) by casting method. Carbohydr. Polym. 2018, 191, 103-111. [CrossRef]

40. Parameswaran, V.; Nallamuthu, N.; Devendran, P.; Manikandan, A.; Nagarajan, E.R. Assimilation of $\mathrm{NH}_{4} \mathrm{Br}$ in polyvinyl alcohol/poly(N-vinyl pyrrolidone) polymer blend-based electrolyte and its effect on ionic conductivity. J. Nanosci. Nanotechnol. 2018, 18, 3944-3953. [CrossRef]

41. Vijayalakshmi, R.; Jayachandran, M.; Sanjeeviraja, C. Structural, electrochromic and FT-IR studies on electrodeposited tungsten trioxide films. Curr. Appl. Phys. 2003, 3, 171-175. [CrossRef]

42. Joraid, A.A.; Alamri, S.N. Effect of annealing on structural and optical properties of $\mathrm{WO}_{3}$ thin films prepared by electron-beam coating. Physica. B Condens. Matter 2007, 391, 199-205. [CrossRef]

43. Haro-Poniatowski, E.; Jouanne, M.; Morhange, J.F.; Julien, C.; Diamant, R.; Fernandez-Guasti, M.; Fuentes, G.A.; Alonso, J.C. Micro-Raman characterization of $\mathrm{WO}_{3}$ and $\mathrm{MoO}_{3}$ thin films obtained by pulsed laser irradiation. Appl. Surf. Sci. 1998, 127, 674-678. [CrossRef] 
44. Sallard, S.; Brezesinski, T.; Smarsly, B.M. Electrochromic stability of $\mathrm{WO}_{3}$ thin films with nanometer-scale periodicity and varying degrees of crystallinity. J. Phys. Chem. C 2007, 111, 7200-7206. [CrossRef]

45. Ge, C.; Wang, M.; Hussain, S.; Xu, Z.; Liu, G.; Qiao, G. Electron transport and electrochromic properties of sol-gel WO 3 thin films: Effect of crystallinity. Thin Solid Films 2018, 653, 119-125. [CrossRef]

46. Yu, H.; Guo, J.; Wang, C.; Zhang, J.; Liu, J.; Dong, G.; Zhong, X.; Diao, X. Essential role of oxygen vacancy in electrochromic performance and stability for $\mathrm{WO}_{3}-\mathrm{y}$ films induced by atmosphere annealing. Electrochim. Acta 2020, 332, 135504. [CrossRef]

47. Kuroki, T.; Matsushima, Y.; Unuma, H. Electrochromic response of $\mathrm{WO}_{3}$ and $\mathrm{WO}_{3}-\mathrm{TiO}_{2}$ thin films prepared from water-soluble precursors and a block copolymer template. J. Asian Ceram. Soc. 2016, 4, 367-370. [CrossRef]

48. Park, Y.T.; Lee, S.H.; Lee, K.T. Electrochromic properties of silver nanowire-embedded tungsten trioxide thin films fabricated by electrodeposition. Ceram. Int. 2020, 46, 29052-29059. [CrossRef]

49. Najafi-Ashtiani, H.; Bahari, A.; Gholipour, S. Investigation of coloration efficiency for tungsten oxide-silver nanocomposite thin films with different surface morphologies. J. Mater. Sci. Mater. Electron. 2018, 29, 5820-5829. [CrossRef]

50. Hoseinzadeh, S.; Ghasemiasl, R.; Bahari, A.; Ramezani, A.H. The injection of Ag nanoparticles on surface of $\mathrm{WO}_{3}$ thin film: Enhanced electrochromic coloration efficiency and switching response. J. Mater. Sci. Mater. Electron. 2017, 28, 14855-14863. [CrossRef]

51. Zhao, Y.M.; Zhang, X.; Chen, X.; Li, W.J.; Wang, L.B.; Ren, F.F.; Zhao, J.P.; Endres, F.; Li, Y. Preparation of $\mathrm{WO}_{3}$ films with controllable crystallinity for improved near-infrared electrochromic performances. ACS Sustain. Chem. Eng. 2020, 8, 11658-11666. [CrossRef] 